\title{
Relationship between white cell count, neuropsychologic outcome, and microemboli in 161 patients undergoing coronary artery bypass surgery
}

\author{
Donald Whitaker, FRCS (Ed), Jan Stygall, MSc, Michael Harrison, FRCP, and Stanton Newman, DPhil
}

From University College London and University College London Hospitals, London, United Kingdom.

Received for publication Sept 2, 2005; revisions received Oct 31, 2005; accepted for publication Jan 3, 2006

Address for reprints: Stanton Newman, DPhil, Unit of Health Psychology, Centre for Behavioural and Social Sciences in Medicine, University College London, 2nd Floor, Wolfson Building, 48 Riding House St, London W1W 7EY (E-mail: s.newman@ ucl.ac.uk)

J Thorac Cardiovasc Surg 2006;131:1358-63 $0022-5223 / \$ 32.00$

Copyright (๑) 2006 by The American Association for Thoracic Surgery

doi:10.1016/j.jtcvs.2006.01.042
Objective: Neuropsychologic impairment remains a problem after coronary artery bypass grafting. Relatively few studies have examined the potential role of the perioperative inflammatory response. This study aimed to determine whether there was any association between perioperative white cell count, microemboli, and cognitive performance after surgical intervention.

Methods: White cell count and differential were prospectively measured perioperatively in 161 patients undergoing coronary artery bypass grafting. A neuropsychologic test battery (9 tests) was administered preoperatively and 6 to 8 weeks postoperatively in all 161 patients. Cerebral microemboli during cardiopulmonary bypass were also recorded by means of a transcranial Doppler scan of the right middle cerebral artery.

Results: There was no correlation between microemboli and white cell counts at any time point. There were weak but significant inverse correlations between both preoperative $(r=-0.19, P=.02)$ and postoperative $(r=-0.21, P<.01)$ white cell count and a measure of overall neuropsychologic test performance (total $z$ change score). There was a weak but significant positive correlation between the neutrophil count 10 minutes after bypass and the intraoperative microemboli count $(r=0.23, P=.01)$.

Conclusions: The correlation between white cell count and neuropsychologic outcome suggests that an inflammatory response might have a role in determining cognitive outcome after coronary artery surgery with cardiopulmonary bypass. The positive correlation between the microemboli during cardiopulmonary bypass and the neutrophil count 10 minutes after bypass is compatible with microemboli contributing to the inflammatory response. The patients' preoperative inflammatory status might also be predictive of the response to surgical intervention.

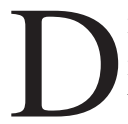
iffuse cerebral injury as reflected in cognitive dysfunction remains an important issue associated with coronary artery bypass grafting (CABG). When defined by a reduction in neuropsychologic (NP) test performance, it affects approximately $20 \%$ to $40 \%$ of patients followed up 2 to 3 months after surgical intervention. ${ }^{1}$ The cause of cerebral injury is probably multifactorial, involving reduced cerebral perfusion, inflammatory responses to surgical intervention, and cerebral microembolism, as detected by means of transcranial Doppler (TCD) scanning. The potential role of microemboli has received the greatest attention, although the relationship between microemboli and NP outcome is complex. Pugsley and colleagues ${ }^{2}$ found a correlation between the number of microemboli recorded during surgical intervention and the incidence of postoperative NP deficits. Clark and associates ${ }^{3}$ subsequently also found that patients with the highest microemboli counts had the worst NP outcome. A study by Neville and coworkers, ${ }^{4}$ however, found that more microemboli occur during valve surgery than during 


$$
\begin{aligned}
& \text { Abbreviations and Acronyms } \\
& \begin{aligned}
\text { ANOVA } & =\text { analysis of variance } \\
\text { CABG } & =\text { coronary artery bypass grafting } \\
\mathrm{CPB} & =\text { cardiopulmonary bypass } \\
\mathrm{NP} & =\text { neuropsychologic } \\
\mathrm{TCD} & =\text { transcranial Doppler } \\
\mathrm{WCC} & =\text { white cell count }
\end{aligned}
\end{aligned}
$$

CABG but without the predicted difference in cognitive outcome. Besides the differential effect of emboli in different parts of the brain and difficulties in determining emboli composition, it is likely that factors other than microemboli are important in determining cognitive outcome.

Although the inflammatory response to CABG surgery has been extensively studied and documented, ${ }^{5}$ there has been relatively little study of the effect of this response on NP outcome, certainly when compared with the study of microembolism. A relationship between the inflammatory response and NP outcome was proposed by $\mathrm{Smith}^{5}$ in 1996, but to our knowledge, the one study thus far to specifically investigate this link found no correlation among a range of inflammatory markers. ${ }^{6}$ It has, however, been found that when heparin-coated bypass circuits are used, there is a reduction in the level of cytokines detectable and also an improved cognitive outcome. ${ }^{7}$ This finding supports the original hypothesis by Smith. ${ }^{5}$ Additionally, a recent study by Matthew and colleagues ${ }^{8}$ found that patients with a low preoperative anti-endotoxin core antibody level were more likely to experience postoperative cognitive dysfunction. The same group has also shown that the use of statin therapy has no effect on either inflammatory response to surgical intervention or cognitive outcome. ${ }^{9}$ A high white cell count (WCC) preoperatively and immediately postoperatively predicted a higher risk for stroke in patients undergoing $\mathrm{CABG}$ or valve surgery. ${ }^{10}$

This study presents a post-hoc analysis that investigates whether the perioperative WCC or neutrophil count correlated with the number of intraoperative cerebral microemboli and with NP outcome.

\section{Materials and Methods}

One hundred ninety-eight patients were recruited for a trial investigating the effect of a leukocyte-depleting filter on NP outcome. Patients were prospectively randomized to receive a leukocyte-depleting filter or one of 2 control filters. ${ }^{11}$ The 3 specific filters used were leukocyte-depleting Leukoguard-6 (Pall Biomedical, Portsmouth, United Kingdom), Avecor Affinity (Medtronic, Bedford, United Kingdom), and AV-6 (Pall Biomedical). The Leukoguard-6 has a $40-\mu \mathrm{m}$ screen and a nonwoven polyester mesh downstream from this, which traps leukocytes. The other 2 filters are standard $40-\mu \mathrm{m}$-screen filters. The filters were placed in the arterial line of the cardiopulmonary bypass (CPB) circuit and were used throughout bypass. As previously reported, ${ }^{11}$ the filters did not have a significant effect on NP outcome or WCC.

Patients scheduled for elective coronary artery bypass surgery in the department of cardiothoracic surgery at The Middlesex Hospital (University College London Hospitals NHS Trust) were invited to participate. We recruited patients of all 6 consultants from the elective waiting list and inpatients awaiting urgent surgical intervention. Prior approval was obtained from the hospital ethics committee, and all patients provided written informed consent before participation.

Patients older than 80 years or having redo procedures were excluded, as were any with a history of transient ischemic attacks or strokes or those with a cardiac arrest in the preceding month. All patients with carotid bruits were excluded. Patients with insulindependent diabetes mellitus, preoperative renal failure (defined as creatinine value $>150 \mathrm{mmol} / \mathrm{L}$ ), or a preoperative leukocyte count outside the normal range of 3 to $11 \times 10^{6} / \mathrm{mm}^{3}$ were excluded.

\section{Surgical and Anesthetic Technique}

Anesthesia, surgical technique, $\mathrm{CPB}$, control of blood pressure and perfusion pressure, control of $\mathrm{pH}$, and $\mathrm{PaCO}_{2}$ all followed a set protocol.

Premedication consisted of morphine $(5-10 \mathrm{mg})$ and hyoscine (0.3-0.4 mg). Diazepam (5-10 mg) or temazepam (10-20 mg) was given according to the anesthetist's preference. Intravenous midazolam was used during insertion of peripheral and central cannulae, as necessary. Induction was carried out with midazolam (2-10 $\mathrm{mg}$ ), fentanyl (0.5-2.0 mg), pancuronium, and/or suxamethonium. Maintenance was with nitrous oxide and oxygen and then isoflurane.

All surgeons used the technique of intermittent cross-clamp fibrillation for myocardial protection. The CPB technique included crystalloid prime and nonpulsatile flow with a flat membrane oxygenator at a flow rate of $2.4 \mathrm{~L} \cdot \mathrm{m}^{-2} \cdot \min -^{1}$ at $37^{\circ} \mathrm{C}$, reducing to $1.8 \mathrm{~L} \cdot \mathrm{m}^{-2} \cdot \min -^{1}$ at $32^{\circ} \mathrm{C}$. Perfusion pressure was maintained between 50 and $70 \mathrm{~mm} \mathrm{Hg}$ by using phenylephrine and phentolamine. $\mathrm{PaCO}_{2}$ was maintained at $5.3 \mathrm{kPa}$ (alpha-stat).

Intraoperative TCD was used to record cerebral blood flow velocity and to monitor microembolic events. Records were taken from the right middle cerebral artery through the temporal window by using a Nicolet EME Pioneer 4040 system (Überlingen, Germany) and a 2-MHz pulsed-wave transducer secured by a headband. Microembolic events were counted throughout CPB.

\section{Blood Tests}

Venous blood ethylenediamine tetraacetic acid samples for full blood count (hemoglobin, platelets, WCC, and differential) were taken (1) preoperatively, (2) at cannulation, (3) after 30 minutes of $\mathrm{CPB}$, (4) 10 minutes after coming off $\mathrm{CPB}$, (5) on the first postoperative day, and (6) on the second postoperative day.

\section{NP Assessments}

One psychologist administered the battery of 9 NP tests. The assessments were conducted during the preoperative week, usually on the day before surgical intervention, and 6 to 8 weeks later during a routine follow-up clinic visit. On each occasion, the patient was tested in the same quiet room. The test battery consisted of the Rey Auditory Verbal Learning Test, Trailmaking A and B, Grooved Pegboard (dominant and nondominant hands), 
TABLE 1. Mean perioperative total WCC and Spearman correlation coefficients between WCC and numbers of microemboli on CPB $(\mathrm{n}=116)$

\begin{tabular}{lcc}
\hline Time & $\begin{array}{c}\text { WCC } \\
\left(\times \mathbf{1 0}^{\mathbf{3}} / \mathbf{m m}^{\mathbf{3}}\right)\end{array}$ & Spearman correlation \\
\hline 1. Preoperative & $7.7(1.9)$ & $r=-0.2, P=.82$ \\
2. Pre-CPB (at cannulation) & $6.8(2.1)$ & $r=0.03, P=.79$ \\
3. On CPB (after 30 min) & $5.1(2.3)$ & $r=0.17, P=.16$ \\
4. Post-CPB (10 min) & $8.5(4.7)$ & $r=0.16, P=.07$ \\
5. Postoperative day 1 & $9.6(2.7)$ & $r=0.07, P=.44$ \\
6. Postoperative day 2 & $11.3(3.3)$ & $r=0.08, P=.41$
\end{tabular}

Figures are means, with standard deviations in brackets. WCC, White cell count; $C P B$, cardiopulmonary bypass.

Symbol Digit Replacement Test, Non-verbal Memory, Letter Cancellation, and Choice Reaction Time, as previously described. ${ }^{12}$

The NP data in this study were analyzed by means of calculating each patient's change in performance on the tests and cumulating this in an overall NP change score. ${ }^{12}$ Each patient's preoperative and postoperative scores were compared to create a change score. Each change score was standardized by dividing it by the standard deviation of the preoperative performance of the group as follows: $\left(z=\left(X_{2}-X_{1}\right) / \mu S D_{1}\right.$, where $X_{1}$ is the preoperative score, $X_{2}$ is the postoperative score, and $\mu \mathrm{SD}_{1}$ is the standard deviation of the preoperative group scores. The standardized or $z$ change scores for individual tests for each individual were summed and divided by the number of tests to produce an overall NP change score for each participant. A positive $z$ change score indicates an improved performance, and the higher the $z$ change score, the better the improvement, whereas a negative score indicates deterioration.

\section{Statistical Analysis}

The 3 filter groups were collapsed for analysis because there was no difference in perioperative WCC, neutrophil count, or NP outcome between the groups. Differences in WCCs over time were analyzed by using repeated-measures analysis of variance (ANOVA). Correlations between WCC and neutrophil count, the number of microemboli, and $z$ change scores were analyzed by using Spearman correlation coefficients.

\section{Results}

A total of 198 patients were recruited into the study. All patients had serial blood testing, and all patients had preoperative NP testing. One hundred sixty-one patients returned for postoperative NP testing (an $84 \%$ follow-up rate). All findings reported on the relationship between blood results and NP change are reported for 161 patients. It was
TABLE 3. Mean perioperative neutrophil count and Spearman correlation coefficients between neutrophil count and number of microemboli on CPB $(n=116)$

\begin{tabular}{|c|c|c|}
\hline Time & $\begin{array}{c}\text { Mean neutrophil } \\
\text { count } \\
\left(\mathrm{SD} ; \times 10^{3} / \mathrm{mm}^{3}\right)\end{array}$ & Spearman correlation \\
\hline 1. Preoperative & $4.7(1.4)$ & $r=-0.08, P=.31$ \\
\hline 2. Pre-CPB (at cannulation) & $4.2(3.6)$ & $r=-0.10, P=.29$ \\
\hline 3. On CPB (after $30 \mathrm{~min}$ ) & $2.8(1.5)$ & $r=0.13, P=.16$ \\
\hline 4. Post-CPB (10 min) & $6.1(2.9)$ & $r=0.23, P=.01$ \\
\hline 5. Postoperative day 1 & $7.9(2.4)$ & $r=0.01, P=.89$ \\
\hline 6. Postoperative day 2 & $9.0(2.9)$ & $r=0.05, P=.61$ \\
\hline
\end{tabular}

Figures are means, with standard deviations in brackets. CPB, Cardiopulmonary bypass.

our aim to perform Doppler microemboli assessment on all patients. However, there was equipment failure for the first 30 patients, and also, some patients did not have an adequate temporal bone window through which the middle cerebral artery could be insonated. One hundred sixteen patients received TCD microemboli assessment. All findings in relation to microemboli are reported for this group.

\section{Total WCC}

As shown in Table 1, there was a characteristic decrease in total WCC during CPB. This was then followed by a postoperative increase. Both the increase and decrease were statistically significant, as determined with repeated-measures ANOVA.

\section{Correlation of WCC With Microemboli}

Table 1 also shows that there was no correlation between the WCC at any of the selected time points and the intraoperative microemboli count.

\section{Correlation of WCC With $z$ Change Scores}

Table 2 shows that there were weak but significant inverse correlations between both preoperative and postoperative WCCs and total $z$ change scores, as well as the $z$ change scores for the individual tests.

\section{Neutrophil Count}

The pattern of a decrease and then increase in total WCC is mainly attributable to the similar decrease and increase in neutrophil count (Table 3). Both the increase and decrease were statistically significant by using ANOVA.

TABLE 2. Spearman correlation coefficients between WCC and overall NP change scores ( $z$ score; $\mathbf{n}=161$ )

\begin{tabular}{ccccccc}
\hline & WCC1: Preoperative & WCC2: Pre-CPB & WCC3: On CPB & WCC4: Post-CPB & WCC5: Day 1 & WCC6: Day 2 \\
\hline Total $r=-0.19, P=.02$ & $r=-0.12, P=.15$ & $r=-0.05, P=.15$ & $r=-0.21, P<.01$ & $r=-0.15, P=.28$ & $r=-0.06, P=.18$
\end{tabular}

WCC, White cell count; NP, neuropsychologic; WCC1 through WCC6, times of sampling of white cell count as per Table 1; $C P B$, cardiopulmonary bypass 
TABLE 4. Spearman correlation coefficients between neutrophil count and overall NP change scores ( $z$ score; $\mathbf{n}=161$ )

\begin{tabular}{cccccc}
\hline N1: Preoperative & N2: Pre-CPB & N3: On CPB & N4: Post-CPB & N5: Day 1 & N6: Day 2 \\
\hline Total $r=-0.12, P=.15$ & $r=-0.03, P=.73$ & $r=-0.03, P=.75$ & $r=-0.18, P=.04$ & $r=-0.12, P=.15$ & $r=-0.03, P=.70$
\end{tabular}

$N P$, Neuropsychologic; $N 1$ through $N 6$, times of sampling as per Table 1; $C P B$, cardiopulmonary bypass.

\section{Correlation of Neutrophil Count With Number of Microemboli Recorded}

Table 3 also shows that there was a weak but significant correlation between the neutrophil count 10 minutes after $\mathrm{CPB}$ and the intraoperative microemboli count.

\section{Correlation of Neutrophil Count With NP \\ $z$ Change Scores}

Table 4 shows that there were weak but significant inverse correlations between the neutrophil count at 10 minutes and total $\mathrm{Z}$ change scores.

\section{Correlation of Microemboli Count With NP $z$ Change Scores}

As had been previously reported,${ }^{11}$ there was no correlation found between microemboli count and NP change score $(r=-0.06, P=.57)$.

\section{Effect of Smoking on WCC}

There was no statistically significant difference between smoking, nonsmoking, and exsmoking groups except preoperatively, when there was a difference between smokers and nonsmokers $\left(\right.$ smokers $=9.0 \times 10^{3} / \mathrm{mm}^{3}$, nonsmokers $=7.6 \times 10^{3} / \mathrm{mm}^{3}[P=.01]$, as shown in Figure 1$)$.

\section{Discussion}

Previous studies of cardiac surgical patients have found a correlation between WCC and both neurologic outcome ${ }^{10}$ and mortality. ${ }^{13}$ However, as far as we are aware, this is the first study to examine the link between WCC and NP outcome. There are 2 separate findings of the present study to be discussed. The first finding is that a higher preoperative WCC predicted a worse NP outcome. This was a weak ( $r=$ $-0.19)$ but significant $(P=.02)$ correlation. By using a median split of the WCC, those with a higher WCC had a significantly worse NP outcome. The second finding is that intraoperative neutrophil count correlates with intraoperative microemboli count and postoperative NP outcome. Intraoperative WCC correlates with postoperative NP outcome. There was positive correlation between the intraoperative microemboli count and neutrophil count 10 minutes after bypass. Both the WCC and neutrophil count 10 minutes after bypass correlated with postoperative NP outcome, with higher counts predicting worse outcome.

The higher preoperative WCC predicting a worse NP outcome in the present study is in accordance with previous findings that WCC is a marker of ischemic heart disease and stroke. ${ }^{14,15}$ Grau and coworkers ${ }^{15}$ studied the 18,558 patients in the clopidogrel versus aspirin in patients at risk of ischemic events (CAPRIE) study and found that leukocyte counts independently predicted ischemic stroke, myocardial infarction, and vascular death. Albert and colleagues ${ }^{10}$ prospectively collected data from 7483 patients undergoing CABG, valve surgery, or both. They found that WCC was significantly higher before surgical intervention and immediately after surgical intervention in the 125 patients who had strokes. The degree of WCC count increase also had an effect on the clinical outcome from stroke, being worse the higher the WCC. Dacey and colleagues, ${ }^{13}$ in a prospective study of 11,270 patients undergoing CABG, found that an increasing preoperative WCC was linearly associated with significantly increased mortality and preoperative stroke. In patients with a preoperative WCC of less than $6 \times 10^{3} /$ $\mathrm{mm}^{3}$, the stroke rate was $1.2 \%$, increasing to a rate of $2.1 \%$ in patients with a WCC of greater than $12 \times 10^{3} / \mathrm{mm}^{3}(P=$ $.003)$. The present study has shown that an increased preoperative WCC also predicts worse NP outcome. This

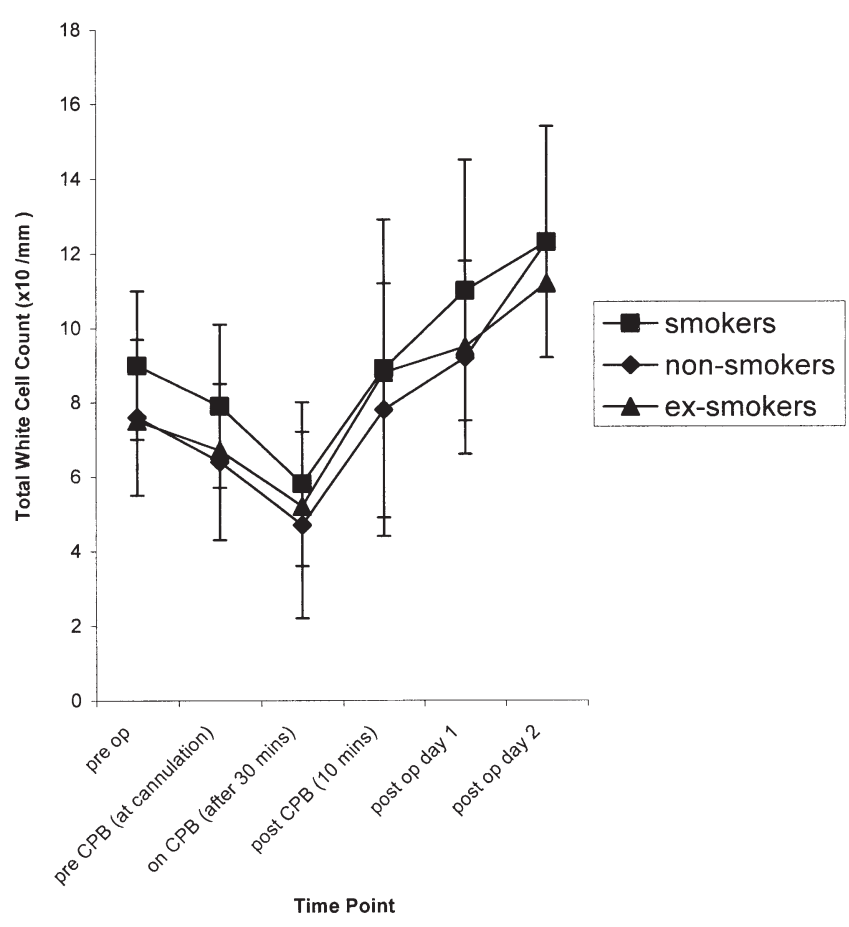

Figure 1. Perioperative white cell count for smokers versus nonsmokers versus exsmokers. CPB, Cardiopulmonary bypass. 
might be because those patients with a high WCC are at a greater risk of a perioperative vascular ischemic event. Smokers are known to have an associated leukocytosis, and Figure 1 shows that smokers in the present study did have a higher preoperative WCC than nonsmokers. However, a high WCC has been shown to be a marker of atherosclerosis, even in nonsmokers, ${ }^{16}$ and therefore the effect might be independent of smoking status.

It has been previously shown ${ }^{17}$ that WCC is correlated with the thickness of aortic arch atherosclerotic plaques. This correlation was found after adjusting for other atherosclerosis risk factors, including smoking. It is therefore possible that those with higher WCCs produce more microemboli from atherosclerotic aortas, thus leading to worse NP outcome. However, in the present study neither preoperative WCC nor neutrophil count correlated with the burden of intraoperative microemboli.

Only some previous studies have found a relationship between WCC or more specific inflammatory markers and NP outcome. Westaby and coworkers ${ }^{6}$ studied 100 patients undergoing $\mathrm{CABG}$ and measured a range of inflammatory mediators, such as interleukin 6 , and NP outcome at 5 days and 3 months after surgical intervention but were unable to find any relationship between the two. They concluded that inflammatory response has no contribution to cognitive decline. However, Westaby and coworkers ${ }^{6}$ were specifically measuring mediators that are increased when there is blood and foreign-surface interaction. The results of the present study suggest that inflammation is in some way invo lved in the process of surgical intervention-related cognitive decline, although because WCC is such a general marker of inflammation, it is not possible to infer more about the mechanism of the effect. Heyer and associates, ${ }^{7}$ in a randomized controlled trial, showed that the use of heparin-bonded bypass circuitry resulted in a reduced inflammatory response as measured by cytokine release and an associated improvement in cognitive outcome after surgical intervention. The results of Heyer and associates ${ }^{7}$ therefore support the findings of the present study and contradict the results of Westaby and coworkers. ${ }^{6}$ The study by Heyer and associates ${ }^{7}$ was significant in being interventional, thus suggesting that by actually reducing the inflammatory response, this causes a reduced cerebral injury. Another anti-inflammatory intervention trial, the use of statins by Mathew and colleagues, ${ }^{9}$ failed to result in any change in inflammatory response to surgical intervention or neurocognitive outcome. It can thus be seen that the literature regarding inflammatory response and NP outcome is contradictory. The results of the present study suggest that the inflammatory response is, in part, contributory to NP outcome after coronary artery bypass surgery. This lends support to the suggestion that the mechanisms involved warrant further study and that specific anti-inflammatory mechanisms might become clinically useful in further reducing the neurocognitive decline that might be associated with surgical intervention.

The relationship between the intraoperative WCCs and neutrophil counts with both intraoperative microemboli counts and postoperative NP outcome is harder to explain. It might mean that an inflammatory process is related to the production of microemboli and their effect on brain function. However, the previously discussed lack of correlation between preoperative $\mathrm{WCC} /$ neutrophil count and numbers of microemboli makes this less likely. It is more likely that microemboli cause an inflammatory reaction, with postbypass WCCs and neutrophil counts increased in correlation with microemboli counts. Microemboli might cause an inflammatory reaction when they lodge in the cerebral and other vasculature.

It must be stated that although the correlations found in the present study are statistically significant, the related effects are small (eg, when a higher preoperative WCC predicts a worse NP outcome, $r=0.19)$. This means that the WCC only accounts for $3.6 \%$ of the NP outcome. It is known that many factors contribute to NP outcome: patient variables, operative variables, and the methods of NP testing. Increasing age, ${ }^{18}$ female sex, ${ }^{19,20}$ atrial fibrillation, ${ }^{21}$ presence of the $\mathrm{P}^{\mathrm{A} 2}$ allele, ${ }^{22}$ and increased severity of aortic atherosclerotic disease ${ }^{18,23}$ are patient factors associated with worse NP outcome. Operative variables, such as acid base balance and method of anesthesia, were all standardized in the present study, as was the NP testing method. It is therefore clear that many factors contribute to NP outcome, and therefore it is not surprising that WCC only accounts for a small proportion of the variation in NP outcome found. WCC is a very nonspecific marker of inflammation, and the fact that an association with NP outcome has been found in the present study indicates its importance.

NP testing is the best currently available way to assess cognitive function perioperatively. However, time constraints mean that the testing has to be performed in about 1 hour, and the battery of tests used has to be carefully selected to cover several cognitive domains and reduce learning effects. Despite all tests in the present study being performed by the same psychologist and conditions being optimized for all patients, external factors and some random variation in test performance might influence NP performance.

In conclusion, the present study has found a correlation between WCC and NP outcome after CABG. In contrast to some previous studies and in accordance with others, the present results suggest that the inflammatory response has a role in determining the cognitive effect of cardiac surgery. The finding of a positive correlation between the number of microemboli produced during $\mathrm{CPB}$ and the neutrophil count 10 minutes after $\mathrm{CPB}$ in the present study might result from microemboli contributing to the inflammatory response. 
This study has also found that the patients' preoperative inflammatory status is involved in predicting the cognitive results of surgical intervention.

\section{References}

1. Newman S, Stygall J. Changes in cognition following cardiac surgery. Heart. 1999;82:541-2.

2. Pugsley W, Klinger L, Paschalis C, Treasure T, Harrison M, Newman S. The impact of microemboli during cardiopulmonary bypass on neuropsychological functioning. Stroke. 1994;25:1393-9.

3. Clark RE, Brillman J, Davis DA, Lovell MR, Price TR, Magovern GJ. Microemboli during coronary artery bypass grafting. Genesis and effect on outcome. J Thorac Cardiovasc Surg. 1995;109:249-58.

4. Neville MJ, Butterworth J, James RL, Hammon JW, Stump DA. Similar neurobehavioral outcome after valve or coronary artery operations despite differing carotid embolic counts. $J$ Thorac Cardiovasc Surg. 2001;121:125-36.

5. Smith PL. The systemic inflammatory response to cardiopulmonary bypass and the brain. Perfusion. 1996;11:196-9.

6. Westaby S, Saatvedt K, White S, Katsumata T, van Oeveren W, Halligan PW. Is there a relationship between cognitive dysfunction and systemic inflammatory response after cardiopulmonary bypass? Ann Thorac Surg. 2001;71:667-72.

7. Heyer EJ, Lee KS, Manspeizer HE, Mongero L, Spanier TB, Caliste X, et al. Heparin-bonded cardiopulmonary bypass circuits reduce cognitive dysfunction. J Cardiothorac Vasc Anesth. 2002;16:37-42.

8. Mathew JP, Grocott HP, Phillips-Bute B, Stafford-Smith M, Laskowitz DT, Rossignol D, et al. Lower endotoxin immunity predicts increased cognitive dysfunction in elderly patients after cardiac surgery. Stroke. 2003;34:508-13.

9. Mathew JP, Grocott HP, McCurdy JR, Ti LK, Davis RD, Laskowitz DT, et al. Preoperative statin therapy does not reduce cognitive dysfunction after cardiopulmonary bypass. J Cardiothorac Vasc Anesth. 2005;19:294-9.

10. Albert AA, Beller CJ, Walter JA, Arnrich B, Rosendahl UP, Priss H, et al. Preoperative high leukocyte count: a novel risk factor for stroke after cardiac surgery. Ann Thorac Surg. 2003;75:1550-7.

11. Whitaker DC, Newman SP, Stygall J, Hope-Wynne C, Harrison MJ, Walesby RK. The effect of leucocyte-depleting arterial line filters on cerebral microemboli and neuropsychological outcome following coronary artery bypass surgery. Eur J Cardiothorac Surg. 2004;25: 267-74.

12. Kong RS, Butterworth J, Aveling W, Stump DA, Harrison MJ, Hammon $\mathrm{J}$, et al. Clinical trial of the neuroprotectant clomethiazole in coronary artery bypass graft surgery: a randomized controlled trial. Anesthesiology. 2002;97:585-91.

13. Dacey LJ, DeSimone J, Braxton JH, Leavitt BJ, Lahey SJ, Klemperer $\mathrm{JD}$, et al. Preoperative white blood cell count and mortality and morbidity after coronary artery bypass grafting. Ann Thorac Surg. 2003;76:760-4.

14. Brown DW, Giles WH, Croft JB. White blood cell count: an independent predictor of coronary heart disease mortality among a national cohort. J Clin Epidemiol. 2001;54:316-22.

15. Grau AJ, Boddy AW, Dukovic DA, Buggle F, Lichy C, Brandt T, et al. Leukocyte count as an independent predictor of recurrent ischemic events. Stroke. 2004;35:1147-52.

16. Huang ZS, Jeng JS, Wang CH, Yip PK, Wu TH, Lee TK. Correlations between peripheral differential leukocyte counts and carotid atherosclerosis in non-smokers. Atherosclerosis. 2001;158:431-6.

17. Elkind MS, Sciacca R, Boden-Albala B, Homma S, Di Tullio MR. Leukocyte count is associated with aortic arch plaque thickness. Stroke. 2002;33:2587-92.

18. Newman MF, Croughwell ND, Blumenthal JA, Lowry E, White WD, Spillane W, et al. Predictors of cognitive decline after cardiac operation. Ann Thorac Surg. 1995;59:1326-30.

19. Sotaniemi KA, Juolasmaa A, Hokkanen ET. Neuropsychologic outcome after open-heart surgery. Arch Neurol. 1981;38:2-8.

20. Di Carlo A, Perna AM, Pantoni L, Basile AM, Bonacchi M, Pracucci $\mathrm{G}$, et al. Clinically relevant cognitive impairment after cardiac surgery: a 6-month follow-up study. J Neurol Sci. 2001;188:85-93.

21. Stanley TO, Mackensen GB, Grocott HP, White WD, Blumenthal JA, Laskowitz DT, et al. The impact of postoperative atrial fibrillation on neurocognitive outcome after coronary artery bypass graft surgery. Anesth Analg. 2002;94:290-5.

22. Mathew JP, Rinder CS, Howe JG, Fontes M, Crouch J, Newman MF, et al. Platelet PlA2 polymorphism enhances risk of neurocognitive decline after cardiopulmonary bypass. Multicenter Study of Perioperative Ischemia (McSPI) Research Group. Ann Thorac Surg. 2001;71: 663-6.

23. Hammon JW Jr, Stump DA, Kon ND, Cordell AR, Hudspeth AS, Oaks TE, et al. Risk factors and solutions for the development of neurobehavioral changes after coronary artery bypass grafting. Ann Thorac Surg. 1997;63:1613-8. 